\title{
GERENCIAMENTO DE RECURSOS HÍDRICOS: DESAFIOS E POTENCIALIDADES DO COMITÊ DE BACIA HIDROGRÁFICA DO RIO PASSO FUNDO
}

\section{Water resources management: challenges and potential of the Committee of River Basin Passo Fundo}

Pedro Daniel da Cunha Kemerich eng.kemerich@yahoo.com.br Universidade Federal do Pampa, Caçapava do Sul, Rio Grande do Sul, Brasil

Luciana Gregory Ritter lucianaritter@yahoo.com Universidade Federal de Santa Maria, Santa Marina, Rio Grande do Sul, Brasil

Vinicius Ferreira Dulac vfdulac@gmail.com Universidade Federal de Santa Maria, Santa Marina, Rio Grande do Sul, Brasil

Rafael Cabral Cruz rafaelcabralcruz@gmail.com Universidade Federal do Pampa, São Gabriel, Rio Grande do Sul, Brasil

Artigo recebido em 14/04/2015 e aceito para publicação em 16/03/2016

RESUMO: Os Comitês de Bacias Hidrográficas são órgãos colegiados onde são debatidas as questões regionais referentes à gestão das águas, desempenhando um papel estratégico na Política de Recursos Hídricos, pois tem o potencial de sintetizar suas diretrizes. Deste modo o objetivo do presente trabalho é avaliar a evolução das ações do Comitê de Bacia do Rio Passo Fundo e seus impactos na implementação do Sistema Estadual de Recursos Hídricos na respectiva bacia. Após a análise das atas do Comitê e destaque dos principais assuntos debatidos, pode-se concluir que o Comitê apresenta problemas relacionados à falta de recursos financeiros, e uma baixa participação dos membros nas reuniões, sendo que a maior dificuldade do comitê está em como motivar a participação da sociedade e de alguns usuários para as questões de interesse coletivo, pois muitos municípios somente apresentam-se atuantes no comitê no momento em que existe algum interesse ou demanda do município a ser sanado. Entretanto, o comitê apresenta-se em estágio avançado de desenvolvimento, tendo o Conselho Estadual de Recursos Hídricos homologado a proposta de enquadramento das águas superficiais que estabelece os parâmetros de qualidade para o uso dos recursos hídricos na Bacia Hidrográfica do Rio Passo Fundo para os próximos vinte anos.

Palavras-Chave - Comitê, participação, recursos.

ABSTRACT: The Watershed Committees are collegiate bodies which are discussed regional issues related to water management, playing a strategic role in water resources policy, as it has the potential to synthesize their guidelines. Thus the aim of this study is to assess the evolution of Committee actions of Passo Fundo River

DOI: http://dx.doi.org/10.1590/1982-451320160106 


\begin{abstract}
Basin and its impact on the implementation of the State System of Water Resources in its basin. After reviewing the minutes of the Committee and highlighted the main issues discussed, it can be concluded that the Committee presents problems related to lack of financial resources, and a low member participation in meetings, with the greatest difficulty the committee is how to motivate society participation and some users for matters of collective interest, since many municipalities have only themselves working on the committee at the time that there is some interest or claim of the municipality to be remedied. However, the committee presents at an advanced stage of development with the State Water Resources Board approved the proposed framework for establishing surface water quality parameters for the use of water resources in the River Basin Fund for the next step twenty years.
\end{abstract}

Keywords - Committee, participation, resources.

\section{INTRODUÇÃO}

Os Comitês de Bacias Hidrográficas estão previstos no Sistema Nacional de Gerenciamento de Recursos Hídricos - SINGRH (instituído pela Lei Federal no 9433/1997), sendo órgãos colegiados onde são debatidas as questões regionais referentes à gestão das águas.

Representantes dos três setores compõe o Comitê de Bacia Hidrográfica: representantes do poder público (União, estados, Distrito Federal e municípios, conforme a abrangência da bacia), usuários das águas e organizações da sociedade civil ligadas a recursos hídricos. O número de representantes de cada 'setor' e os critérios para sua indicação são estabelecidos nos regimentos internos dos próprios comitês (algumas leis estaduais também explicitam esta composição), limitando a representação dos poderes executivos à metade do total de membros (CARDOSO, 2003).

No caso das bacias sob domínio do Estado do Rio Grande do Sul, a legislação (Lei Estadual ${ }^{\circ}$ 10.350/1994 - Política Estadual de Recursos Hídricos e o Decreto Estadual $\left.n^{\circ} 37.034 / 1996\right)$ determinam o percentual de vagas de representação das organizações sociais em $80 \%$ nos Comitês de Bacia, divido igualmente entre entidades representativas de usuários da água e da população da bacia. O Estado tem 7 vagas, duas obrigatórias dos órgãos Estaduais fiscalizadores.

Cada comitê conta com uma diretoria composta de um presidente e um vice-presidente. Além disso, atendendo ao disposto na Lei Estadual $\mathrm{n}^{\circ}$ 10.350/94, a qual institui o Sistema Estadual de Recursos Hídricos do Rio Grande do Sul - SERH-
RS e regulamenta o funcionamento dos comitês, estes elaboram seu respectivo regimento interno. Normalmente, define-se a partir do Regimento Interno que o organismo conte com uma secretaria executiva e com uma comissão permanente de assessoramento. O secretário executivo é escolhido pela diretoria com o aval do comitê. A comissão permanente de assessoramento, cujo número de integrantes e forma de escolha varia conforme o Comitê tem a função de secundar a diretoria na preparação e na execução das atividades do comitê (CÁNEPA; GRASSI, 2001).

Os comitês desempenham um papel estratégico na Política Nacional de Recursos Hídricos, pois tem o potencial de sintetizar suas diretrizes. Esta, ao preconizar uma gestão descentralizada - no nível espacial das bacias, participativa e integrada - faz com que o Comitê de Bacia se configure em um espaço institucional, o qual pode ser caracterizado como uma arena de tomada de decisões para o compartilhamento de interesses e integração de políticas dos setores usuários da água e da sociedade civil.

Assim, o êxito de seu funcionamento em certa medida significa o êxito da própria política das águas. Sua legitimidade tem sido conferida não apenas pela própria lei e pelas políticas nacional e estaduais, mas por políticas paralelas que têm sido implementadas tanto no âmbito nacional como no estadual e, em alguns casos, até no municipal (CARDOSO, 2003).

Porém, as diferenças espaciais e temporais da disponibilidade hídrica regional proporcionam diferentes condições de apropriação do recurso hídrico, assim possibilitando a emergência de interesses diversos (GWP, 2009).

Este mesmo lugar de participação, de 
cooperação e de construção de alianças é, também, um espaço de conflitos que emergem em virtude dos diferentes sujeitos que o compõem - diferentes interesses, diferentes posições na escala social e política, das formas de resistência, organização e participação. Fracalanza et al. (2009, p.57, grifo nosso), compreende o Comitê como "parte de um sistema de gestão das águas de caráter descentralizado e centrado na noção de poder social que media as relações entre Estado e Sociedade Civil também por conflitos".

Considerando que a integração de políticas e diretrizes ocorrem em um contexto estratégico (SARAVANAN et al., 2009) e que a construção dos diálogos entre as políticas também é permeada por conflitos, pressupõe-se a necessidade de um potencial de negociação e articulação para que as prioridades de gestão sejam estabelecidas no contexto de uma efetiva presença e participação multissetorial no âmbito do Sistema de Recursos Hídricos.

Deste modo o objetivo do presente trabalho é avaliar a evolução das ações do Comitê de Bacia do Rio Passo Fundo e seus impactos na implementação do Sistema Estadual de Recursos Hídricos na respectiva bacia.

\section{LOCALIZAÇÃO E CARACTERIZAÇÃO DA ÁREA DE ESTUDO}

A bacia hidrográfica do rio Passo Fundo situase ao norte do Estado, drenando uma área de 4.853,16 $\mathrm{Km}^{2}$, conforme a Figura 1.

Figura 1. Bacia Hidrográfica do Rio Passo Fundo

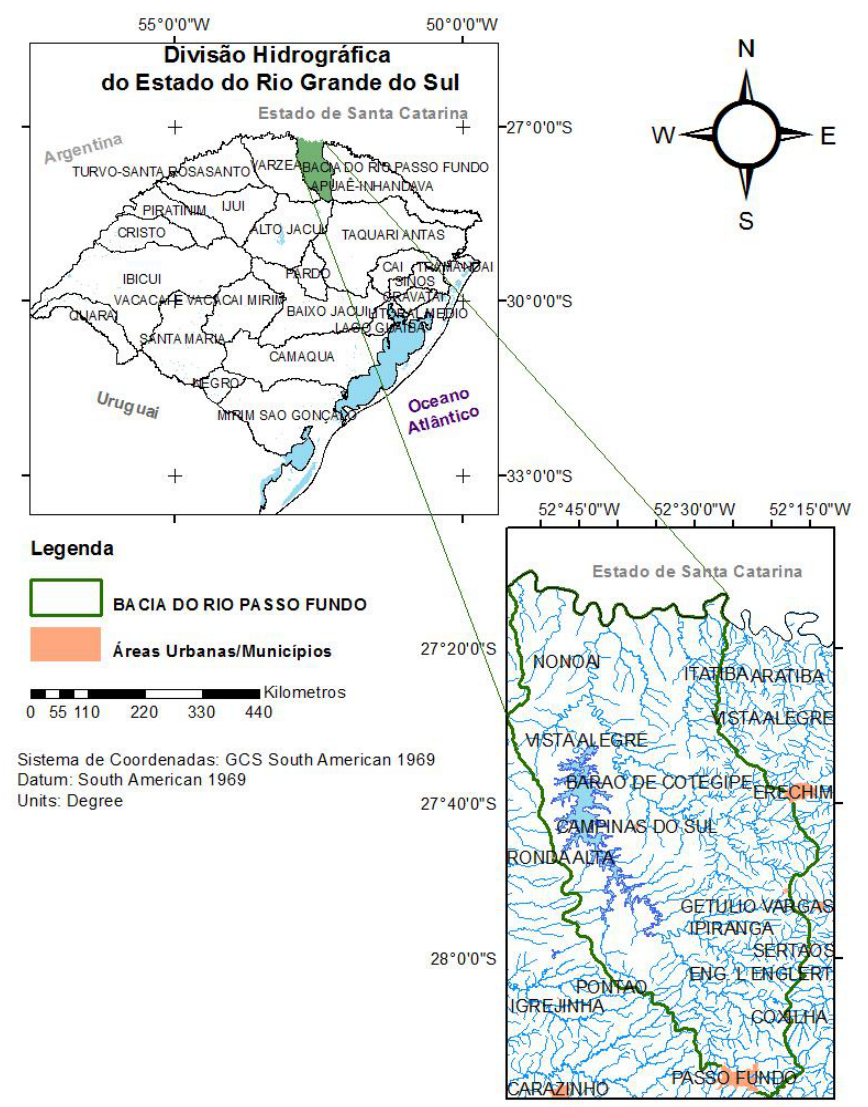

Elaboração dos autores. 
Inicialmente foi criado o Comitê de Gerenciamento da Bacia Hidrográfica dos rios Passo Fundo - Várzea, sendo este posteriormente dividido, e o Comitê de Gerenciamento da Bacia Hidrográfica do rio Passo Fundo criado pelo Decreto Estadual $n^{\circ}$ 42.961, de 23/03/2004, tendo suas categorias sido alteradas em consonância com a resolução $\mathrm{CRH} /$
RS 004/2004 pelo Decreto no 43.225 de 13/07/2004. Seus principais formadores são os rios Passos Fundo, Índio e Erechim, arroios Butiá e Timbó (SEMA, 2010). A bacia abrange total ou parcialmente 30 municípios, totalizando uma população de 160.077 habitantes, conforme a Tabela 1.

Tabela 1. População urbana e rural por município

\begin{tabular}{|c|c|c|c|c|c|c|}
\hline Município & $\begin{array}{l}\text { Área do município } \\
\text { na bacia }(\%)\end{array}$ & $\begin{array}{l}\mathrm{P} \text { o p } \\
\text { Urbana }\end{array}$ & $\begin{array}{l}\text { P o p . } \\
\text { Rural }\end{array}$ & $\begin{array}{l}\text { Pop. Urbana } \\
\text { (Bacia) }\end{array}$ & $\begin{array}{l}\text { Pop. Rural } \\
\text { (Bacia) }\end{array}$ & $\begin{array}{l}\text { Pop. Total } \\
\text { (Bacia) }\end{array}$ \\
\hline Barão de Cotegipe & 67,41 & 3.697 & 2.822 & 3.697 & 1.902 & 5.599 \\
\hline Barra do Rio Azul & 1,66 & 383 & 1.645 & 0 & 27 & 27 \\
\hline $\begin{array}{l}\text { B e } n \text { j a } m \text { i } n \\
\text { Constant do Sul }\end{array}$ & 100,00 & 304 & 1.952 & 304 & 1.952 & 2.256 \\
\hline Campinas do Sul & 100,00 & 4.185 & 1.403 & 4.185 & 1.403 & 5.588 \\
\hline Coxilha & 59,71 & 1.741 & 1.175 & 1.741 & 702 & 2.443 \\
\hline Cruzaltense & 100,00 & 367 & 1.906 & 367 & 1.906 & 2.273 \\
\hline Entre Rios do Sul & 100,00 & 1.953 & 1.148 & 1.953 & 1.148 & 3.101 \\
\hline Erebango & 81,74 & 1.906 & 975 & 1.836 & 797 & 2.633 \\
\hline Erechim & 15,66 & 87.562 & 5.383 & 0 & 843 & 843 \\
\hline Erval Grande & 100,00 & 2.433 & 2.861 & 2.433 & 2.861 & 5.294 \\
\hline Estação & 70,11 & 5.192 & 894 & 0 & 627 & 627 \\
\hline Faxinalzinho & 100,00 & 1.173 & 1.440 & 1.173 & 1.440 & 2.613 \\
\hline $\begin{array}{l}\text { Gramado dos } \\
\text { Loureiros }\end{array}$ & 25,02 & 480 & 1.890 & 0 & 473 & 473 \\
\hline Ipiranga do Sul & 100,00 & 645 & 1.338 & 645 & 1.338 & 1.983 \\
\hline Itatiba do Sul & 84,16 & 1.633 & 2.941 & 0 & 2.475 & 2.475 \\
\hline Jacutinga & 100,00 & 2.284 & 1.283 & 2.284 & 1.283 & 3.567 \\
\hline Nonoai & 65,30 & 9.043 & 3.284 & 9.043 & 2.144 & 11.187 \\
\hline Passo Fundo & 25,37 & 178.186 & 5.114 & 76.839 & 1.297 & 78.136 \\
\hline Paulo Bento & 100,00 & 477 & 1.613 & 477 & 1.613 & 2.090 \\
\hline Pontão & 60,57 & 1.514 & 2.390 & 0 & 1.448 & 1.448 \\
\hline Ponte Preta & 100,00 & 482 & 1.358 & 482 & 1.358 & 1840 \\
\hline Quatro Irmãos & 100,00 & 847 & 888 & 847 & 888 & 1.735 \\
\hline
\end{tabular}

Fonte: SEMA, 2008. 
No que se refere às atividades econômicas, observa-se o uso intensivo do solo para a produção de grãos, principalmente monoculturas de soja, milho, trigo e aveia. A forte presença das lavouras, em sucessivos momentos (plantio, desenvolvimento vegetativo das culturas e colheitas) marca o cenário regional. Nas regiões de relevo bem acentuado ou ondulado como, por exemplo, na área de transição do Planalto Médio e Alto Uruguai, observam-se pequenas propriedades de subsistência. A produção na região está sendo diversificada através da suinocultura e avicultura. Com exceção do município de Passo Fundo, que apresenta um perfil e condições de atrair grandes indústrias, a bacia não conta com atividades industriais expressivas (FEPAM, [200]). Sendo assim, a estimativa das demandas hídricas superficiais anuais na bacia, em função dos usos é sintetizada na Figura 2.

Figura 2. Gráfico do percentual estimado para as demandas hídricas superficiais anuais, Bacia Hidrográfica do Rio Passo Fundo

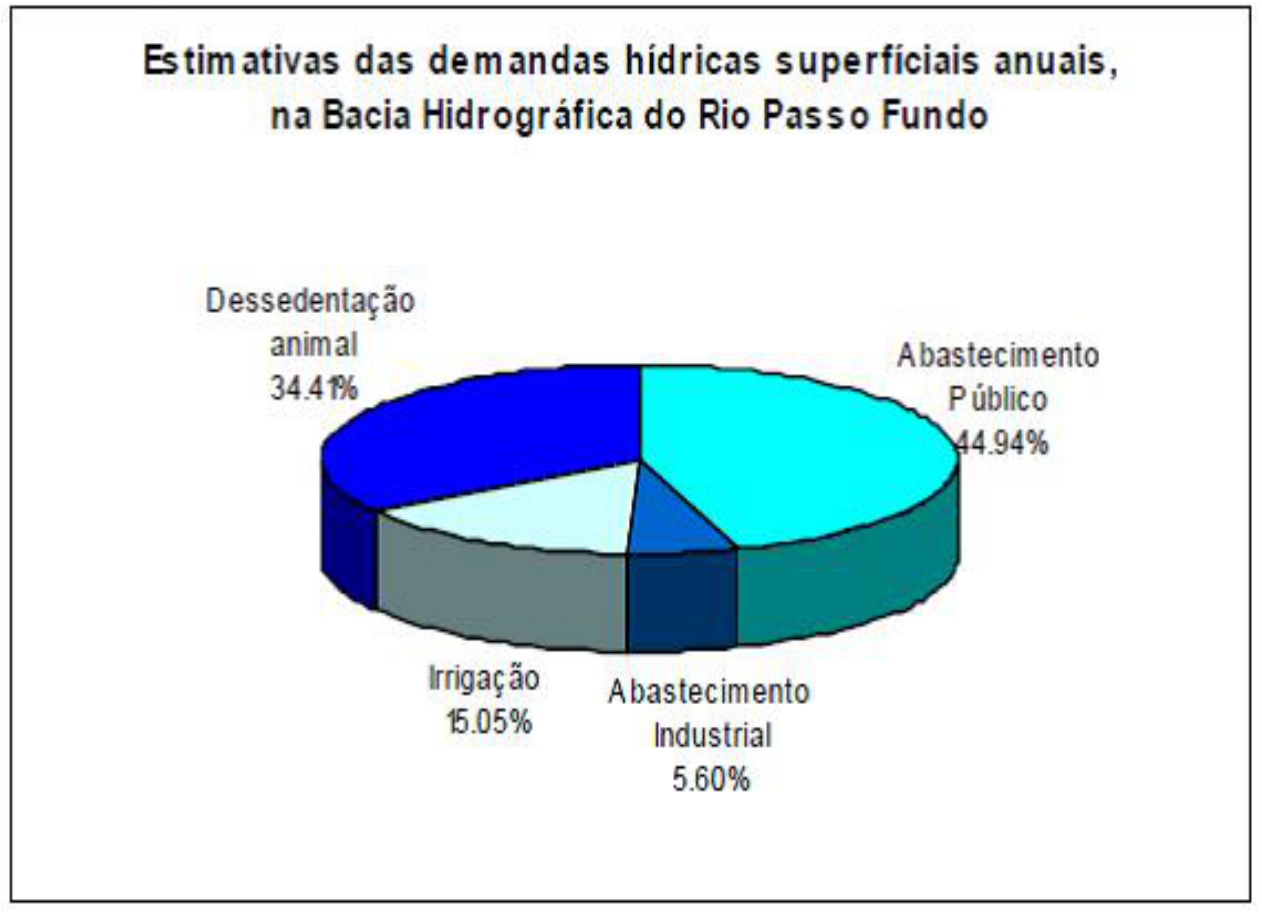

Fonte: SEMA, 2008

A falta de saneamento básico e a ausência de tratamento de dejetos cloacais nos municípios inseridos na bacia comprometem alguns tributários e, principalmente, a parte superior do rio Passo Fundo (FEPAM, [200-]).

\section{METODOLOGIA}

Este estudo teve como objeto de avaliação as ações do Comitê de Bacia Hidrográfica do Rio Passo Fundo, sendo estas selecionadas a partir da leitura e sistematização das respectivas Atas de Reuniões Ordinárias e Extraordinárias, discussões, deliberações e projetos aprovados. As atas do comitê foram obtidas junto ao site do mesmo na web (http:// www.upf.br/cbhpf/), totalizando 58 atas, as quais correspondem ao período de 08 de março de 2006 a 30 de outubro de 2012.

Sendo as deliberações, em geral, assuntos encaminhados e votados de forma paritária pelo comitê, tratando-se de recomendações referentes a Planos; Estudos; Legislações entre outros, que dependem da ação efetiva de outros organismos, em geral do Estado, União, ou dos municípios, para sua execução. 
Os projetos aprovados no comitê podem ser considerados como uma das ações mais efetivas dessas instâncias, uma vez que concorrem ao recebimento de recursos financeiros, principalmente do Fundo de Recursos Hídricos do Rio Grande do Sul - FRH-RS, para sua implementação. Além disso, os projetos ali aprovados abrem a oportunidade de concretização de uma serie de demandas que envolvem tanto a melhoria da qualidade dos recursos hídricos como a minimização dos conflitos que envolvem a relação água e território.

A classificação utilizada para as deliberações e projetos, a qual é baseada em Cury (2005), sendo adaptada por Dulac et al. (2012) e modificada neste artigo é apresentada em tabelas. A Tabela 2 apresenta as deliberações e os respectivos aspectos avaliados.

Tabela 2. Classificação das deliberações e discussões

\begin{tabular}{|c|c|}
\hline Deliberação & Aspecto Avaliado \\
\hline Administrativo & Auto-regulamentação administrativa do comitê \\
\hline Normativo & Regulamentação regional de políticas de recursos hídricos \\
\hline Financeiro & Critérios para a aplicação de recursos \\
\hline Planos/Estudos e Projetos & Estudo e confecção de Planos e Projetos para as bacias \\
\hline Eventos & $\begin{array}{l}\text { Realização, apoio e participação em eventos de gestão ambiental e } \\
\text { de recursos hídricos na bacia }\end{array}$ \\
\hline
\end{tabular}

Fonte: Cury (2005); Dulac et al.(2012), organização dos autores.

Já a classificação dos projetos é apresentada na Tabela 3, estando baseada nos seguintes aspectos avaliados:

Tabela 3. Classificação dos projetos

\begin{tabular}{|c|c|}
\hline Projeto & Aspecto Avaliado \\
\hline Planos/Estudos e Projetos & Aprovação da elaboração de Planos e Projetos para as bacias \\
\hline Obras & Aprovação de medidas estruturais na bacia \\
\hline Ações Complementares & $\begin{array}{l}\text { Relacionam-se a implementação de instrumentos de sistemas de gestão } \\
\text { dos recursos hídricos }\end{array}$ \\
\hline Educação Ambiental & Realização de ações de educação ambiental nas bacias \\
\hline
\end{tabular}
Fonte: Cury (2005); Dulac et al. (2012), organização dos autores.

Esta classificação foi modificada em função de características especificas do comitê, devido ao seu reduzido número de deliberações, fazendo-se necessário considerar os assuntos discutidos mesmo sem aprovação e/ou encaminhamento.

\section{RESULTADOS E DISCUSSÃO}

Avaliação das deliberações aprovadas em Atas do Comitê do Rio Passo Fundo
Ao longo do período analisado, foram verificadas 189 deliberações nas atas do comitê, quando avaliadas por assunto, totalizando $100 \%$ das deliberações contidas nas atas, conforme Tabela 4. 
Tabela 4. Total de deliberações aprovadas por assunto

\begin{tabular}{lll}
\hline Deliberação & Total Geral & $(\%)$ \\
\hline Administrativo & 61 & 32,28 \\
Eventos & 31 & 16,4 \\
Financeiro & 17 & 8,99 \\
Normativo & 3 & 1,59 \\
Planos/Estudos e Projetos & 77 & 40,74 \\
\hline Total Geral & 189 & 100 \\
\hline
\end{tabular}

Elaboração dos autores.

Observa-se que o comitê se mostrou atuante, apresentando um elevado índice de deliberações, conforme Figura 3, sendo o auge do total de deliberações no ano de 2008, e após o mesmo, o comitê passou por um período de declínio no total de deliberações.

Figura 3. Número de deliberações aprovadas ao ano

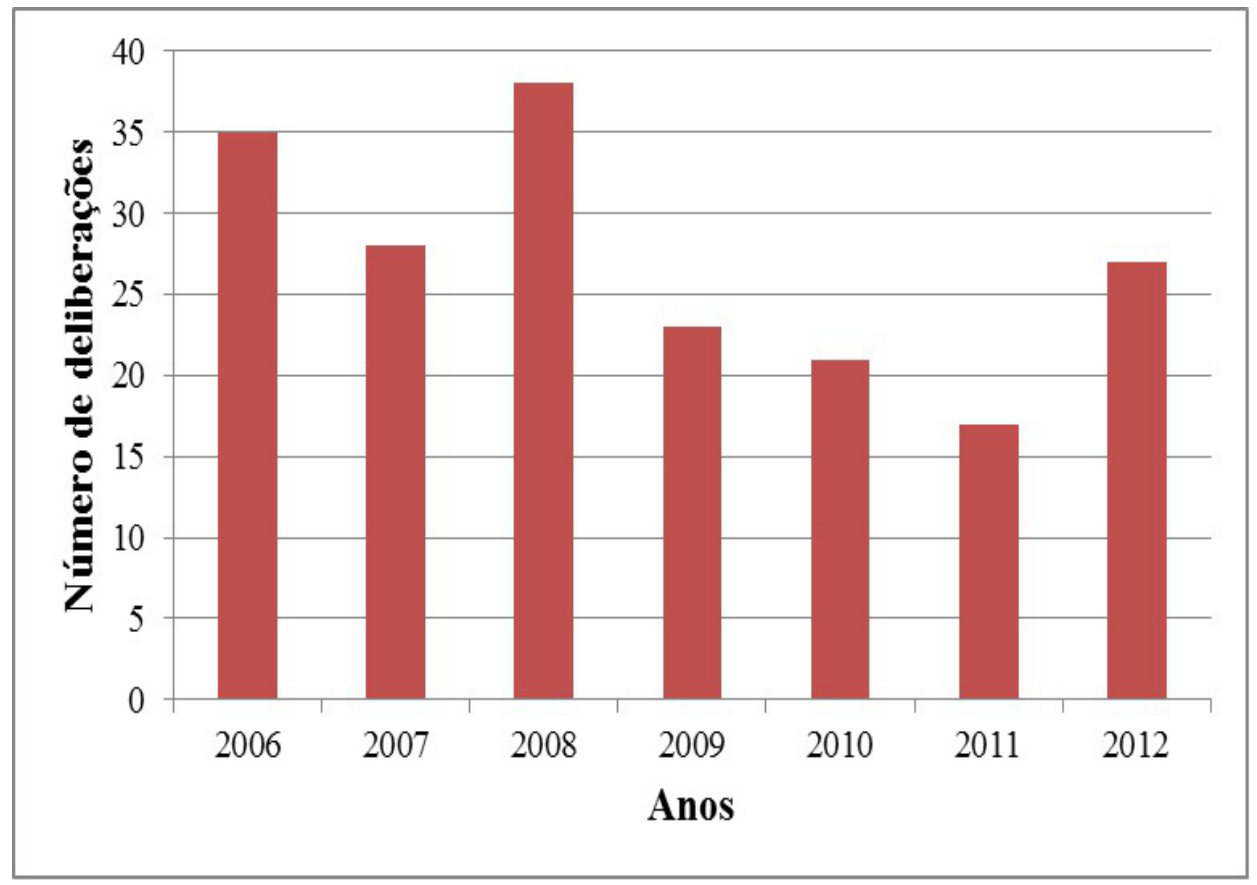

Elaboração dos autores.

Em relação às variações no número de deliberações em função dos anos de mandato eleitoral, Cury (2005) verificou que ocorre uma diminuição da quantidade de deliberações em anos de início e final de mandatos municipais.

Observa-se que no CBHPF os anos de início e final de mandatos municipais, apresentaram número crescente de deliberações, assim como constatado no Comitê de Gerenciamento da Bacia Hidrográfica dos 
Rios Vacacaí e Vacacaí-Mirim por Kemerich et al. (2013). Já os anos com menor número de deliberações referem-se aos entremeios dos mandatos municipais, corroborando com os resultados de Dulac et al. (2012) ao analisar o Comitê de Bacia Hidrográfica do Rio Santa Maria. Demonstrando uma possível deficiência quanto à integração das prefeituras no Sistema de Recursos Hídricos, no que se refere à participação junto aos Comitês de Bacia em suas tomadas de decisão, durante a gestão pública.

Analisando o total de deliberações aprovadas porassunto, oitemPlanos/EstudoseProjetosapresenta preponderância, totalizando 77 deliberações, o que corresponde a $40,74 \%$ do total de deliberações aprovadas. Estes resultados demonstram que o comitê se apresenta de forma atuante, realizando um esforço quanto ao autoconhecimento da realidade regional, como instrumentação para ação sobre os recursos hídricos. Neste item destacam-se indicações decorrentes de estudos referentes à implantação de empresas, parques, além de indicações decorrentes da escrita do Plano de Bacia, o qual ainda não foi implantado.

Em seguida, destacam-se as deliberações de caráter administrativo, as quais totalizam 61 deliberações, correspondendo a $32,28 \%$ do total. Sendo os anos de 2006 e 2008, os que apresentaram maior número de deliberações de caráter administrativo, predominantemente relacionadas a ações de organização interna do comitê, como criação do regimento interno, criação do calendário de reuniões, relatórios de gestão e criação de câmaras técnicas.

Os anos que apresentaram o maior número de deliberações administrativas coincidem com os anos que apresentaram o maior número de deliberações referentes a planos/estudos e projetos, o que demonstra que a partir da organização interna do comitê, este passa a tornar-se mais atuante perante as questões referentes à bacia hidrográfica.

As deliberações relacionadas ao item Eventos correspondem a 31 deliberações, $16,4 \%$ do total, as quais correspondem principalmente à realização de palestras, cursos e eventos de capacitação.

Já as deliberações de caráter financeiro representam $8,99 \%$ do total, com 17 deliberações, sendo as mesmas predominantemente referentes a deliberações do orçamento interno. O CBHPF apresentou grandes dificuldades referentes à questão de recursos financeiros para a manutenção do mesmo, sendo publicados artigos nos Jornais Zero Hora e Correio do Povo sobre a situação do repasse dos recursos aos Comitês, além da busca de fontes alternativas de recursos.

Em função dos comitês gaúchos não terem implementado a cobrança pelos usos da água, suas ações dependem integralmente dos recursos do Fundo Estadual de Recursos Hídricos. Isso não apenas limita significativamente a escala de atuação do comitê, como suas ações se restringem a elaboração de estudos e projetos, sem uma atuação em obras propriamente ditas que seria o verdadeiro indicador de alcance de resultados.

De maneira geral, o item Normativo apresenta 3 deliberações, representando 1,59\% do total, demonstrando que o comitê ainda avança timidamente em relação a regulamentação regional das políticas de recursos hídricos.

Cabe ressaltar que o Comitê do Rio Santa Maria (implantado desde 1994) também apresentou como predominantes deliberações administrativas e referentes a planos estudos e projeto no inicio de suas atividades. Posteriormente o referido Comitê apresentou mais intensamente deliberações normativas (Dulac et al., 2012).

\section{Avaliação dos projetos aprovados em Atas do Comitê de Bacia Hidrográfica do Rio Passo Fundo}

Durante o período avaliado foram aprovados 15 projetos, com destaque para as aprovações na categoria planos/estudos e projetos como é evidenciado na Tabela 5. O que demonstra a atuação do comitê não só quanto à aprovação da intenção de realizar estudos na bacia e na discussão de indicações decorrentes destes estudos, mas também na aprovação e concretização da elaboração destes planos e projetos para a bacia. 
Tabela 5. Total de projetos aprovados por assunto

\begin{tabular}{lll}
\hline Natureza do Assunto & Total Geral & $(\%)$ \\
\hline Ações Complementares & 2 & 13,33 \\
Educação Ambiental & 3 & 20 \\
Obras & 2 & 13,33 \\
Planos/Estudos e Projetos & 8 & 53,34 \\
\hline Total Geral & 15 & 100 \\
\hline
\end{tabular}

Elaboração dos autores.

Diferentemente do que pode ser verificado no que se refere à quantidade de deliberações aprovadas ao ano, como pode ser observado na Figura 4, não foi possível verificar nenhuma relação entre as fases de aumento ou declínio no número de projetos aprovados com os períodos de início, final e entremeios de mandatos municipais e estaduais.

Figura 4. Número de projetos aprovados ao ano

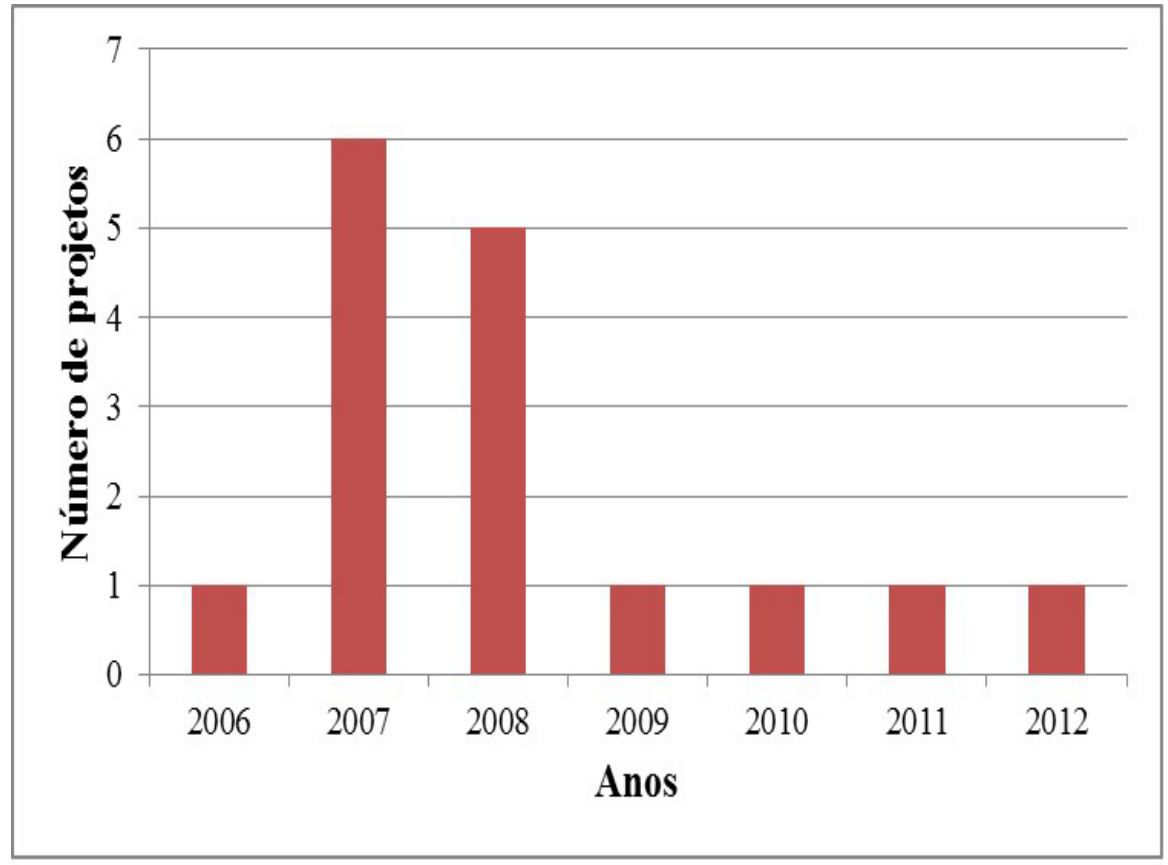

Elaboração dos autores.

Ao analisar o total de projetos aprovados, observa-se a predominância dos que tratam sobre planos/estudos e projetos, com 8 projetos aprovados, representando $53,34 \%$ do total de projetos aprovados, sendo o ano de 2008 o que apresentou um maior número de aprovações. Dentre os projetos aprovados, destacam-se os que se referem ao Plano de Bacia do Comitê, como a aprovação da elaboração do Termo de Referência, a aprovação da Proposta de Enquadramento (o qual foi efetivado com a aprovação 
da Resolução CRH no 120/2012) e a aprovação da elaboração de um newsletter com notícias a respeito do andamento dos trabalhos do Plano de Bacia.

Já os projetos aprovados referentes a ações de educação ambiental representam $20 \%$ do total, com 3 projetos aprovados, todos no ano de 2007 , sendo estes referentes a projetos de limpeza e reflorestamento das margens do Rio Passo Fundo com alunos das escolas, além da aprovação da confecção de folders e de um vídeo de conscientização ambiental a serem utilizados nos projetos de educação ambiental, o que ratifica que após a estruturação interna do comitê, intensificada em 2006, novos rumos podem ser tomados através das ações propostas pelo mesmo em busca da manutenção e preservação dos recursos hídricos da bacia.

Os projetos aprovados referentes a obras correspondem a $13,33 \%$ do total, com 2 projetos aprovados, sendo uma das obras aprovadas a canalização de um trecho de quinhentos metros do arroio Lajeado Paiol Grande na área urbana do município de Barão do Cotegipe, em função do problema de inundações, sendo que a mesma foi aprovada para atender à necessidade da Prefeitura na liberação dos recursos, mas com ressalvas quanto ao cumprimento das condicionantes da licença ambiental. Outra obra foi definida pelo promotor do município de Passo Fundo, o qual decidiu tomar medidas jurídicas, obrigando o fechamento de todos os poços artesianos.

As ações complementares também correspondem a $13,33 \%$ do total, com 2 projetos aprovados, sendo os mesmos a votação da vazão de referência para o Plano de Bacia e a definição de que se lutará pelo cumprimento da Lei, que prevê a criação de três Agências ou em último caso, formar uma Agência central, porém, composta por mais dois escritórios nas demais Regiões Hidrográficas.

\section{CONSIDERAÇÕES FINAIS}

O Comitê de Bacia Hidrográfica do Rio Passo Fundo apresenta-se em estágio avançado de desenvolvimento, tendo o $\mathrm{CRH}$ homologado a proposta de enquadramento das águas superficiais que estabelece os parâmetros de qualidade para o uso dos recursos hídricos na Bacia Hidrográfica do Rio Passo Fundo para os próximos 20 anos, através da Resolução ${ }^{\circ} 120$ que está publicada no Diário Oficial do Governo do Estado do dia 03 de janeiro de 2013 e possui força de Lei, através do qual busca-se realizar o planejamento da conservação, em quantidade e qualidade, da água na bacia hidrográfica.

Observou-se que o Comitê apresenta problemas relacionados à falta de recursos financeiros, e uma baixa participação dos membros nas reuniões, sendo que a maior dificuldade do comitê está em como motivar a participação da sociedade e de alguns usuários para as questões de interesse coletivo, pois muitos municípios somente apresentam-se atuantes no comitê no momento em que existe algum interesse ou demanda do município a ser sanado.

A escassez de recursos torna-se, em longo prazo, um fator de desmobilização social em torno do comitê, o que representa uma ameaça para a existência dessas instituições, haja vista que os comitês passam a ter um papel deliberativo, mas exclusivamente do ponto de vista político, tendo em vista que o mesmo não possui recursos para executar/implementar estruturalmente - as suas decisões, mas tão somente na forma de estudos e projetos e mesmo estes em quantidade reduzida.

\section{REFERÊNCIAS}

CÁNEPA, M.E.; GRASSI, L.A.T. Os comitês da Bacia no Rio Grande do Sul - uma experiência histórica. Ciência e Ambiente, Santa Maria, Universidade de Santa Maria, n. 21, 2001.

CARDOSO, M.L. de M. Desafios e potencialidades dos comitês de bacias hidrográficas. Ciência e Cultura. São Paulo, vol. 55, n. 4., out./dez. 2003.

CURY, J.F. A Gestão Integrada de Bacias Hidrográficas: A Abertura de uma oportunidade para o Desenvolvimento Sustentável do Alto Paranapanema (1994-2004). 2002. 350f. Tese (Doutorado em Estruturas Ambientais Urbanas) - Faculdade de Arquitetura e Urbanismo, Universidade de São Paulo, São Paulo, 2002. 
DULAC, V.F. et al. Classificação das deliberações e projetos aprovados pelo Comitê de Bacia Hidrográfica do Rio Santa Maria. In: $3^{\circ}$ Congresso Internacional de Tecnologias para o Meio Ambiente. 2012, Bento Gonçalves, Anais... Bento Gonçalves, 2012.

\section{FUNDAÇÃO ESTADUAL DE PROTEÇÃO} AMBIENTAL HENRIQUE LUIZ ROESSLER FEPAM, [200-]. U20 - Passo Fundo. Disponível em: $<$ http://www.fepam.rs.gov.br/qualidade/bacia_uru_ passofundo.asp $>$. Acesso em 17 out. 2014.

FRACALANZA, A.P.; CAMPOS, V.N.; MEDEIROS, Y.D. Governança das águas da região metropolitana de São Paulo (Brasil) - o caso do Comitê da Bacia Hidrográfica do Alto Tietê. In: . Dimensões político institucionais da governança da água na América Latina e Europa. São Paulo: Annablume, pp. $42-59,2009$.

GWP (Global Water Partnership). (2009). A handbook for integrated water resource management in basins. GWP, Paris, 2009. Disponível em: < www.gwpforum. org >. Acesso em: 15 mar. 2013.

KEMERICH, P. D. da C.; MARTINS, S. R.; KOBIYAMA, M.; BURIOL, G. A.; CRUZ, R. C.; RITTER, L. G.; DULAC, V. F. Efetividade do comitê de gerenciamento de recursos hídricos na bacia hidrográfica dos rios Vacacaí e Vacacaí-Mirim. Revista Recursos Hidricos, v. 34, n. 2, novembro de 2013. pp. 13-24. DOI: $10.5894 / \mathrm{rh} 34 \mathrm{n} 2-2$

SARAVANAN, V. S.; McDONALD, G. T.; MOLLINGA, P. P. "Critical review of Integrated Water Resource Management: Moving beyond polarised discourse". Natural Resources Forum, v. 1 , n. 33 , 2009, pp. 76 - 86. DOI: 10.1111/j.14778947.2009.01210.x

\section{SECRETARIA ESTADUAL DO MEIO AMBIENTE} - SEMA. (2008). Relatório Anual Sobre a Situação dos Recursos Hídricos no Estado do Rio Grande Do Sul Edição 2007/2008. Rio Grande do Sul.

\section{SECRETARIA ESTADUAL DO MEIO AMBIENTE}

- SEMA. (2010). Bacia Hidrográfica do rio Passo Fundo. Disponível em: <http://www.sema.rs.gov.br/ conteudo.

asp?cod_menu $=58 \&$ cod_conteudo $=6015>$. Acesso em: 17 out. 2014. 